\title{
Taking Theology To Youth Ministry
}

Andrew Root; Grand Rapids: Zondervan, 2012; 110 halaman.

B

uku "Taking Theology to Youth Ministry" adalah buku teologi dogmatis yang ditulis melalui dan untuk pelayanan kaum muda. Tujuan penulisan buku ini memberikan sebuah paradigma berpikir yang teologis dalam mengerjakan pelayanan kaum muda. Berlatar dari kisah fiksi seorang pelayan penuh waktu bernama Nadia, Andrew Root mengajukan beberapa pertanyaan penting seputar pelayanan kaum muda sebagai pintu masuk pembahasannya. Pertanyaan-pertanyaan itu adalah: Apa tujuan dari pelayanan kaum muda? Untuk apa pelayanan kaum muda ada? Bagaimana pelayanan kaum muda melakukan teologi? Bagaimana teologi memberikan arti kepada pelayanan? Dan bagaimana kita memahami peranan seorang pelayan kaum muda? Pertanyaanpertanyaan ini menjadi dasar pembahasan dari keenam bab di dalam bukunya ini.

Pada bab pertama, Root menjelaskan latar belakang tokoh fiksi yang ia ciptakan. Nadia tidak tamat dari seminari tetapi pengalamannya sebagai youth worker membuka peluang untuknya melayani sebagai pelayan penuh waktu di sebuah gereja yang jemaatnya berpandangan konservatif. Dijelaskan juga tentangJerry, seorang gembala senior yang enerjik, pragmatis dan hanya memiliki sedikit perhatian terhadap pemikiran teologi dan filsafat. Lalu Erica, asisten gembala adalah seorang thinker yang khotbah-khotbahnya menantang jemaat untuk berpikir lebih dalam. Di antara kedua rekan kerja seperti inilah Nadia melayani sebagai gembala kaum muda.

Akan tetapi tantangan di awal pelayanannya justru datang dari jemaat yang terbagi di dalam 2 kubu. Kubu yang pertama menginginkan Nadia untuk membangun sebuah pelayanan yang dapat menjangkau orang muda untuk hadir. Sebab itu pelayanan kaum muda harus dibuat semenarik mungkin agar anak-anak mereka tetap datang ke gereja. Sedangkan kubu yang kedua, menginginkan sebuah pelayanan yang konsentrasinya adalah agar kaum muda di gereja mereka mengenal Tuhan Yesus dengan baik, menghidupi imannya dan terlibat di dalam pelayanan. Dalam kondisi jemaat yang seperti inilah Nadia melayani. Dalam tahun pertama, ia berhasil membangun hubungan dengan kaum muda yang ia layani meski ia bertanya, "Apa yang sebenarnya menjadi tujuan dari pelayanan kaum muda?" Pertanyaan ini mengarahkan Nadia untuk berpikir lebih jauh tentang pelayanan yang sedang ia kerjakan. Dan layaknya sebuah perjalanan, kisah Nadia dirangkai dengan baik

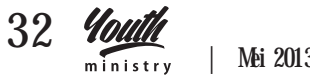


oleh Root sehingga semua pertanyaan tersebut terjawab.

Apa yang dilakukan oleh Andrew Root di dalam buku kecilnya ini adalah mengarahkan pembacanya untuk berpikir bahwa pelayanan kaum muda bukanlah sekedar menyediakan aktivitas-aktivitas yang menggiring anak muda untuk datang atau hanya sekedar membuat kaum muda memiliki pengetahuan alkitab teologi yang baik. Pelayanan kaum muda adalah sebuah journey yang membawa para pelayan untuk berpartisipasi di dalam apa yang sedang Allah kerjakan di dunia ini. Para pelayan kaum muda mempunyai tugas untuk mencari tahu dan membuat kaum muda sadar tindakan Allah di dalam dan melalui dirinya.

Root memberikan penekanan bahwa teologi adalah hamba dari pelayanan (ministry), karena teologi adalah pencerminan dari tindakan Allah di dalam pelayanan, yang kita alami melalui pelayanan kita dan di dalam dan melalui gereja (hal.54). Dalam bab ini Root berusaha untuk menguraikan kembali akar dari pembentukan sebuah teologi. Ia melihat bahwa teologi bermula dari tindakan Allah di dalam context tertentu di dalam sejarah umat-Nya, dimana dalam tindakan Allah tersebutlah kita menemukan content dari karakter Allah. Dan menurut Root, pelayanan kaum muda bersifat telogis karena tujuannya adalah berpartisipasi di dalam tindakan Allah dengan berpikir, merasakan dan mengambil bagian di dalamnya.

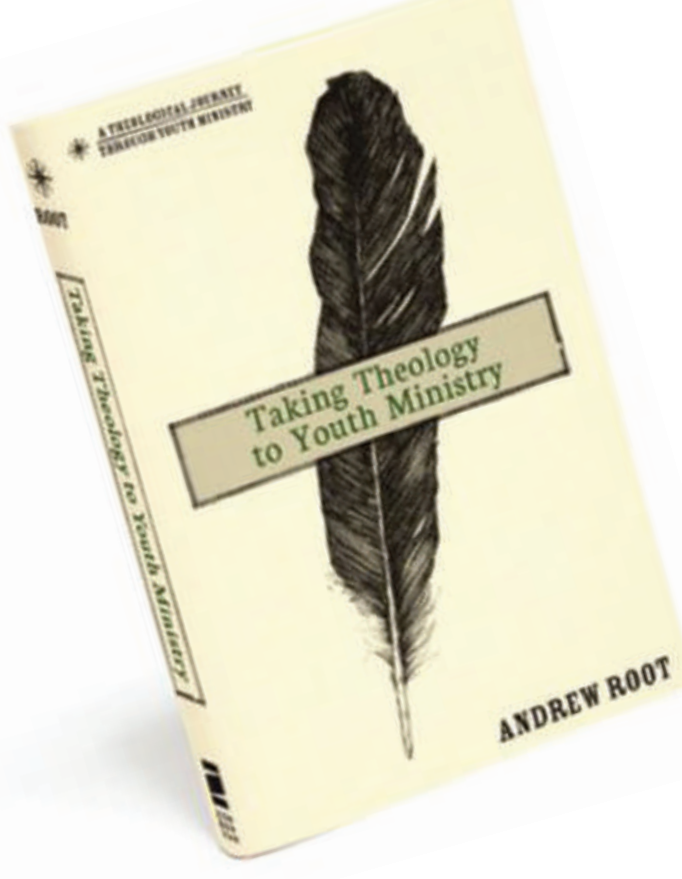

Pemahaman inilah yang akan mendorong seorang pelayan kaum muda untuk melihat dirinya sebagai seorang teolog di dalam pelayanannya. Context dan content tidak terpisah tetapi bersatu di dalam apa yang sedang Allah kerjakan di dalam kehidupannya dan kehidupan kaum muda yang ia layani.

Meskipun buku ini hanya terdiri dari 110 halaman, tetapi memberikan asupan teologis yang memadai untuk menantang pembacanya melihat pelayanan kaum muda sebagai ranah berteologi. Dan kisah fiksi dari Nadia, membuat pembahasan teologis menjadi sesuatu yang praktis dan relevan di dalam pelayanan, sehingga selayaknya Taking Theology to Youth Ministry menjadi salah satu buku yang wajib dibaca bagi mereka yang memberikan dirinya berpartisipasi di dalam tindakan Allah di dalam diri kaum muda. 


\section{Project}

\section{Buku PA Spiritualitas}

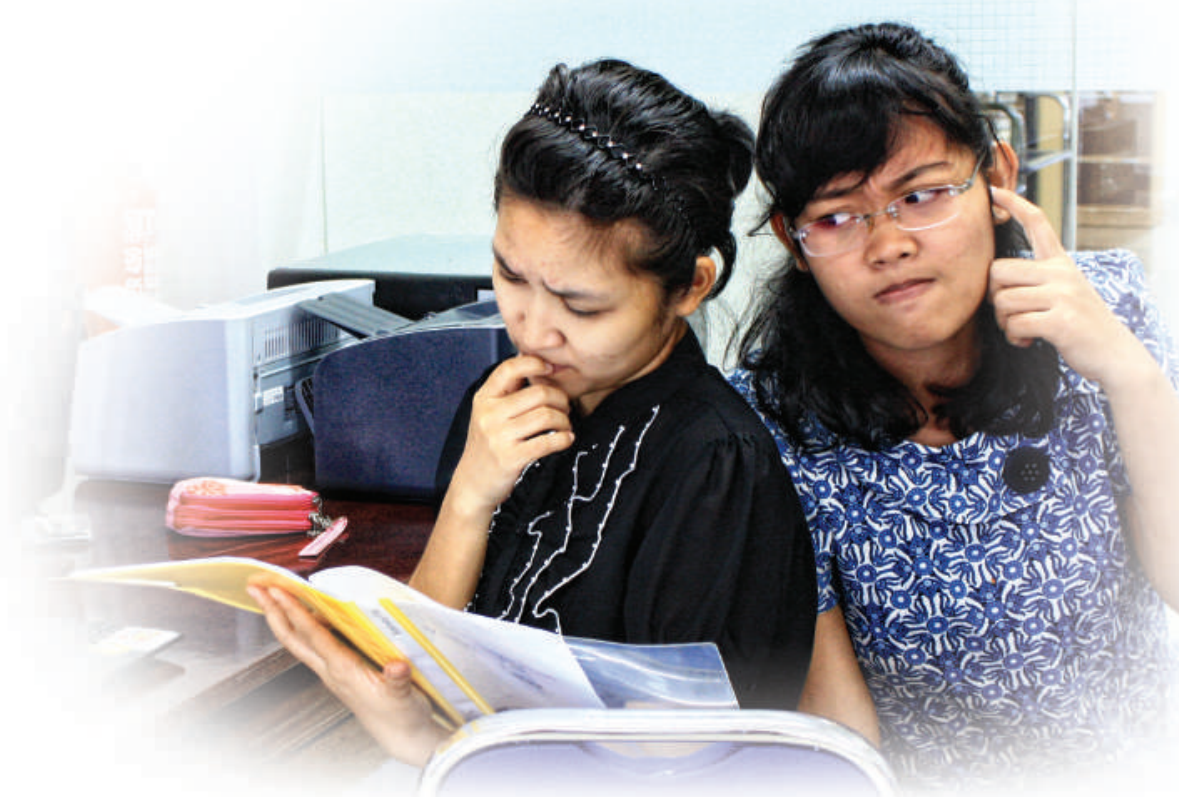

B

erawal dari pemikiran pentingnya membangun spiritualitas bagi kaum muda, maka tim dari bidang minat pelayanan kaum muda yang beranggotakan mahasiswa-mahasiswi STTAA beserta dosen pembimbing yakni Ibu Astri Sinaga dan Ibu Casthelia Kartika merencanakan proyek pembuatan buku Pendalaman Alkitab mengenai Spiritualitas bagi Remaja. Tepatnya pada Mei 2012, pertemuan pertama bidang minat pelayanan kaum muda melakukan pembahasan mengenai proyek yang hendak dilakukan dan tahap pertama yang akan diambil. Pertemuan tersebut menghasilkan keputusan bersama bahwa tahap pertama dalam pembuatan buku PA Spiritualitas adalah membedah buku Messy Spirituality yang ditulis oleh Mike Yaconelli.

Pada September 2012, tim bidang minat pelayanan kaum muda melakukan bedah buku Messy Spirituality. Melalui buku tersebut, tim mendapati beberapa konsep mendasar berkenaan spiritualitas yang dipaparkan oleh Mike Yaconelli. Dalam bukunya, Mike Yaconelli menyatakan, "Spirituality is not a formula; it is not a test. It is a relationship. Spirituality is not about competency; it is about intimacy. Spirituality is not about perfection; it is about connection" (hal. 13). Lebih lanjut,

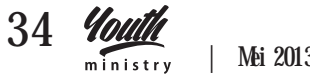


Yaconelli juga mengungkapkan "Spirituality looks like whatever you and I look like when we're thinking about Jesus, when we are trying to find Jesus, when we are trying to figure out what real Christianity looks like in the real world" (hal. 26).

Setelah melakukan bedah buku dan mendapatkan beberapa konsep penting yang dipaparkan oleh Yaconelli, maka tim melakukan tahap kedua, yakni membahas metode pembuatan PA. Dalam tahapan ini, ibu Astri Sinaga dan ibu Casthelia Kartika memberikan arahan berkenaan dengan metode yang akan digunakan dalam pembuatan PA. Hasilnya terbentuklah kerangka "chunkies" PA yang terdiri dari lima tahapan dan tujuan masing-masing, yakni :

(1) Sign In: tahap awal tiap anggota dapat masuk ke dalam topik.

(2) Browsing: melihat latar belakang perikop Alkitab.

(3) Downloading: Pembahasan Firman Tuhan dan mendiskusikan masalah.

(4) Conforming: menarik kesimpulan dan mengevaluasi diri.

(5) Updating: mendorong tiap anggota untuk melakukan dan mengalami perubahan hidup.

Setelah kerangka telah dibentuk, proyek buku PA memasuki tahap ketiga, yakni penetapan tema-tema yang akan dibahas. Ibu Astri Sinaga dan Ibu Casthelia Kartika, selaku dosen pembimbing bidang minat pelayanan kaum muda, memberikan enam tema spiritualitas yang terinspirasi dari tulisan Yaconelli dalam buku Messy Spirituality. Keenam tema tersebut kemudian dikerjakan oleh enam mahasiswa/ i STT Amanat Agung, yakni Willi-

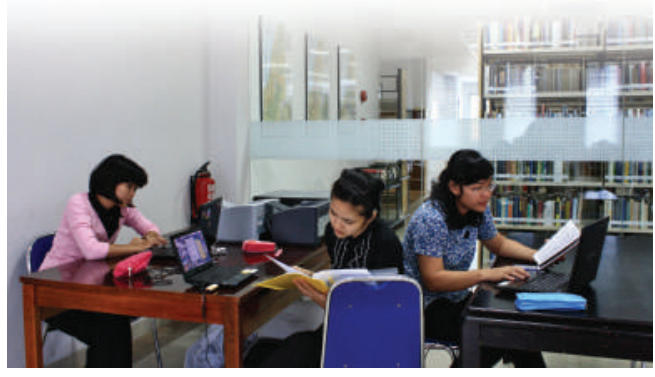

em Ferdinandus, Gilly, Ivan Christian, Amelia Runtuwene, Michele Turalaki, Richard Lengkong,.

Pada November 2012 dan Februari 2013 diadakan pertemuan bidang minat pelayanan kaum muda untuk melakukan simulasi tema-tema yang sudah dikerjakan oleh enam penulis. Simulasi PA yang dilakukan ini merupakan tahap keempat dari proyek buku PA. Dengan kerjasama antar anggota, diadakanlah simulasi PA yang dipimpin oleh enam penulis. Masukan dan saran diberikan oleh tiap anggota kepada enam penulis untuk memperbaiki bahan PA. Kemudian tahap kelima adalah simulasi PA yang melibatkan anak-anak remaja di berbagai gereja. Dalam tahap ini, tiap anggota bidang minat pelayanan kaum muda berupaya melakukan simulasi di gereja-gereja tempat pelayanan masing-masing. Tiap masukan dan saran yang telah didapat dari tahap kelima tersebut diberikan kepada enam penulis untuk revisi terakhir.

Dengan melakukan revisi terakhir setelah melewati tahap kelima, maka proyek buku PA Spiritualitas dari bidang minat pelayanan kaum muda telah mencapai tahap terakhir, yaitu final editing. Melalui kerjasama antar anggota dan bimbingan dari Ibu Astri Sinaga dan Ibu Casthelia Kartika, maka proyek PA Spiritualitas kini telah diterbitkan menjadi buku PA Spiritualitas. Soli Deo Gloria. 


\section{Segera Terbit...}

\section{Buku PA Kreatif Kaum Muda}

6) Cly Cpisitubality

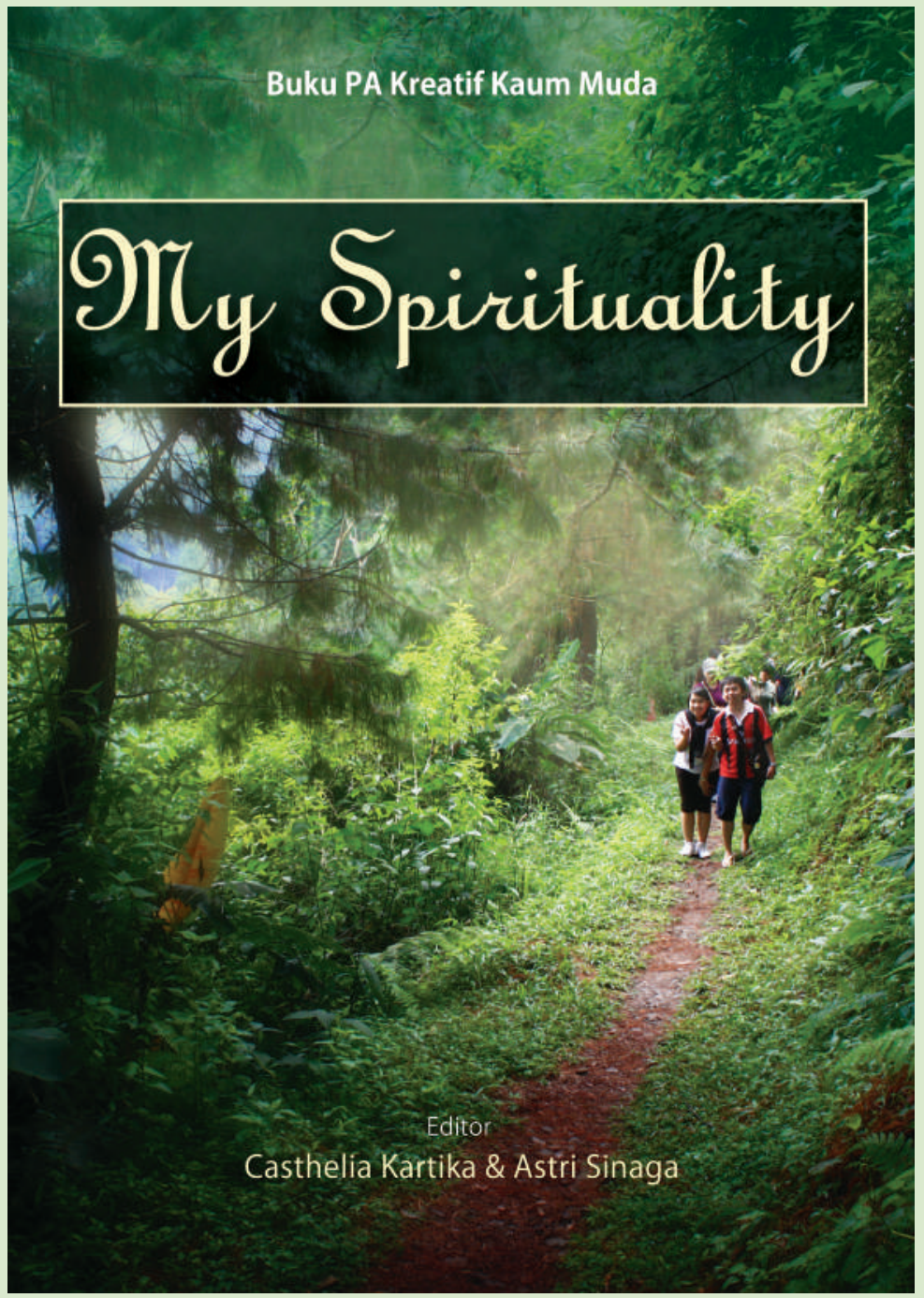




\section{Telah Terbit!}
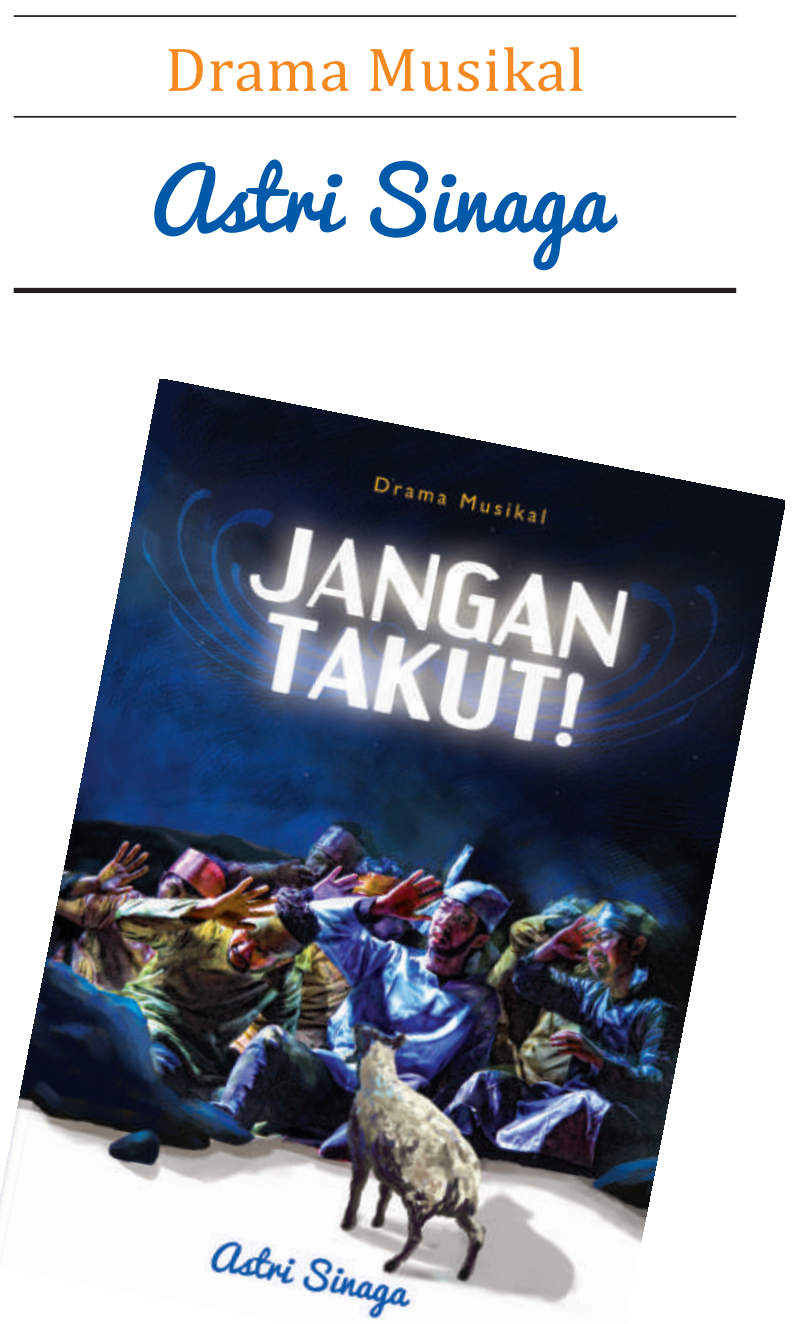

Pusat Studi dan Pengembangan Pelayanan Kaum Muda (PSPPKM) 